\title{
First-generation Turkish women in the 2060 neighbourhood of Antwerp
}

Creating places for interpersonal connection

\author{
Ruth Segers
}

TVGEND 21 (4): 325-340

DOI: 10.5117/TVGN2018.4.003.SEGE

\begin{abstract}
This paper reports on a small-scale case study using an intersectional approach that reflects on sense of place in first-generation Turkish migrant women who migrated to Belgium in the 1970s and who live in Antwerp 2060 (Belgium). It shows how migrant women have taken on efforts to re-enact and renegotiate places in search of interpersonal connection within their new environment. The case study focuses on three significant time periods in the life cycle of the women: before migration, in the extended arrival period, and today. It is empirically supported by semi-structured personal interviews covering place-related life stories situated at the intersection of four social identity categories, i.e. age, gender, socio-economic background, and culture. The analysis illustrates how the benefit of economic migration for these migrant women comes with the sacrifice of social connectedness, a consequence of their 'deduplicated' feeling of belonging.
\end{abstract}

Keywords: intersectionality, Turkish migrant women, sense of place, belonging, interpersonal connection

This paper seeks to shed light on first-generation Turkish women's experience and (evolving) attitude regarding sense of place in the 2060 neighbourhood of Antwerp. Documenting and analysing this particular social group in this particular locality responds to a deep felt sentiment to question the relationship between place and a universal social need to deeply connect with others (Baumeister \& Leary, 1995). How women born in Turkey relate 
to a Belgian urban neighbourhood and (not) develop a sense of belonging has been insufficiently researched. This is surprising because local experiences, sense of place, and feelings of belonging are key to understanding this generation in this neighbourhood.

The memorable municipal elections of 1988, when the ultra-right wing party Vlaams Blok [Flemish Block] became the third biggest party in Antwerp, revealed major cultural tensions in this neighbourhood (Moulaert \& Christiaens, 2010). We can roughly distinguish three historical 'population layers' (Blommaert, 2014). The first population layer consists of 'native' elderly working-class people. Since the 1970s, 206o Antwerp harbours a resident community of Turkish and Moroccan guest worker migrants and their families. Their communities are historically the most ethnic minorities there and form the second layer. During the 1988 election period, they stood for 30 to 40 per cent of the 35 , ooo inhabitants (Divercities, 2013). Meanwhile, an influx of people from Eastern Europe and sub-Saharan Africa in the 199os has further diversified the ethnical composition of the 206o neighbourhood and created a third population layer. When looking at the last decade, a fourth layer could be added to this stratification: well off and highly educated young native Belgians with a distinctly different profile from the first population layer responded to the low real estate prizes of the neighbourhood and went to live there (Blommaert, 2014). Taken together, as many as 146 nationalities reside in the neighbourhood at present; Turkish inhabitants are listed under the statistical denominator 'West Asians', which represent $17 \%$ of a population of 44,00o (Stad Antwerpen, 2018).

In the slipstream of the 1988 elections, inhabitants of diverse ethnic origins have been interviewed extensively about their experiences with living in this multi-cultural neighbourhood (Panorama Jambers, 1988). In the 199os, the national, regional, and local inner city policies, reinforced by the EU Urban policy, made a clear break with the policies of the 1980s. They actively promoted a reversal of the negative image of this railway station neighbourhood through investing in a diversity of social, cultural, and economic activities under the flag of Integrated Area Development (IAD), exploited by the BOM [Buurtontwikkelingsmaatschappij], a laboratory for social innovation involving initiatives such as training, participation, housing, and the improvement of public space (Moulaert, 2000; Moulaert \& Christiaens, 2010). In 2005-2008, the city invested in the urban reconversion project Park Spoor Noord, which turned a large railway yard into a multifunctional public park of 44 acres. Hereafter, public investments in the neighbourhood have considerably decreased. 
What has been missing throughout, though, is the involvement of initial first-generation Turkish migrant women in public debates. This can be explained by their absence from the public place, or their disinclination to enter in conversation in public, or because they have been overlooked by public authorities or researchers. Only recently, at the occasion of $5^{\circ}$ years of Turkish migration to Belgium, their experiences have been documented, but mainly through the eyes of their husbands (Decommere, 2014; Erfgoedcel Mijn Erfgoed, 2014). Hence, this study focuses on experiences of Turkish women who followed their guest worker husbands in the 1970s to live in the 206o neighbourhood of Antwerp.

This paper reveals how our sense of place (and such related things as our degrees of mobility) are not only gender specific, but also have a very local character (Massey, 1994). The central question is: how do the women involved in this study craft spaces for meaningful interpersonal interaction and pursue their social lives within public space or in its folds? The scholarly notion 'sense of place', defined as a 'communally held sense of appropriate behaviour, and a context for engaging in and interpreting action' (Harrison \& Dourish, 1996), is used to highlight the meaning that spaces acquire through active and engaged participation in them, turning those spaces into meaningful places. Sense of place is what makes a space specific; it not only relates to the physical characteristics of the environment, it also refers to the affect and meanings (including memories and associations) and the activities afforded by the place, including the social interactions associated with it. New members of any culture, such as new arrivals in a neighbourhood, learn the local culture and the role they play in it by socialisation. Learning involves time. Although sense of place is essentially a cultural phenomenon, it certainly does not exclude that it is also a very personal thing. It is, concurrently, an individual process of receiving, reconstructing, and communicating in a narrative way the unique identity of space, which then becomes place (Rose, 1995).

There are four sections in this paper. The first section introduces a classic intracategorical approach to intersectionalism. It goes on to discuss some target group specific particularities that needed attention in order to apply interviews as a research method. It further describes the social location of the selected women, followed by the researcher's situatedness vis-àvis the involved women. The second section presents a narrative of sense of place of the involved women over three periods in time: before migration, during the extended arrival period, and today. Each time period highlights particular intersections between social identity categories that have predominated in creating a sense of place in that specific time period. The 
third section reflects on the narrative and discusses three issues that play a dominant role in the involved women's attitudes, sentiments, and behaviour regarding place: language education, gender, and belonging. The final section exposes a deduplicated feeling of belonging as an important factor of keeping public place in this neighbourhood a male-dominated realm.

\section{Setting up a small-scale case study amongst first-generation Turkish women}

By focusing on a particular social group, at neglected dimensions of intersection, I seek to reveal the complexity of lived experience of this group and the diversity and difference within this group. I therefore use a classic intracategorical approach to intersectionalism as introduced by Crenshaw (1991). In this single-group analysis, complexity derives from the analysis of a social location at the intersection of four single dimensions of four categories, rather than at the intersection of a full range of dimensions of a full range of categories (intercategorical approach) or none at all (anticategorical complexity) (MacCall, 2005). The considered dimensions are (1.) being female, (2.) living in the 206o neighbourhood with a particular socio-economic background, and (3.) having been born before migration in the 1970 s (4.) in Turkey (see Illustration 1). Only those dimensions have been chosen because they sufficiently characterise a target group whose voice does not seem to have been of significance in previous analysis about the use of and design for public place in the given neighbourhood. This study does not determine the complex texture of day-to-day life of the involved individual women nor their individual psychological make-up. The topic of this study is the reality of the individual experience of a social identity, because it is this experience that is connected to socio-structural incidences of power that maintain systems of inequity (Lutz, 2002).

However, intersectionality and social inequalities should not be reduced only to the classic analysis of oppression and discrimination through the lenses of gender, class, and race. They also need to be considered from the perspective of the 'privileged within' a social group (Lutz, 2002). It is these 'privileged within' aspects that can give clues as to how the perceived oppression is managed or could be managed. In order to reveal the voice of the selected social group and perceive its active engagement as an 'identity', this study uses narratives or life stories (Prins, 2006).

This paper operationalises the four mentioned social identity dimensions involved in this case study by: 
1 reflecting on the particular situatedness and partiality between the people involved in the interviews;

2 focusing on three significant time periods in the life cycle of the selected women - before migration, in the extended arrival period, and today which highlights an evolving evolution in intersectional relations;

3 identifying the social identity category that is most frequently stressed by interviewees at certain moments in their narration. Then contextually analysing the relevance of this identity category in relation to the other categories.

This case study is predominantly based on semi-structured personal interviews of two hours with women inhabitants of 206o Antwerp. A typical interview consisted of two parts: it started with me raising some pre-conceived questions about the selected dimensions of identity categories. Next, I continued with questions that triggered personal stories regarding experiences with place. How did the women experience public places in their locality of origin and in their current locality? Which social activities did they enjoy most in both places? Where is 'at home' and why? After each interview, I took time to visit the neighbourhood places that were mentioned during the interview.

Through the Voluntary Service [Vrijwilligersdienst] of the city of Antwerp, I found the contact details of a translator for the interviews. The women in the research target group have difficulty to express themselves in Dutch, and I do not speak Turkish. Dudu, also a first-generation Turkish woman and brought up in the 206o neighbourhood, was listed as a volunteer in educational programmes organised by the city of Antwerp and in Vagga cgg (Centre for Mental Healthcare) to inform elderly Turkish migrants on issues as diverse as waste selection and female sexuality. During our first meeting, she agreed on working as a translator for me on a volunteer basis. Her relational skills and natural link with the Turkish community in Antwerp, personally and professionally, proved to be invaluable for this project. According to her estimation, a total of 30 women would fit the four social identity criteria. Whenever she found someone willing to give an interview, she called me to set an appointment.

Over a period of six months, we retained nine interviewees who fully fitted the selected social location, as indicated in grey in Illustration 1. They had arrived in Belgium between 1973 and 1979. At the interview moment, their ages ranged from 57 to 72 , with the exception of two daughters of 42 and 44. Illustration 2 shows that eight interviewees were born in the rural fringes of Central Anatolia. One woman was born in the urban context of Gaziantep (Southeast Anatolia). 


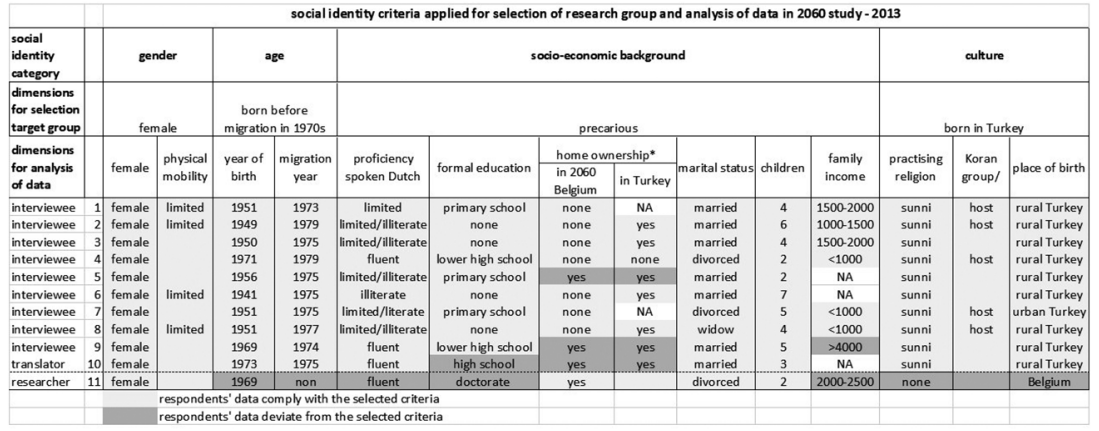

Illustration 1 Social identity criteria for the selection of the research group and the analysis of empirical findings in 2060 study - 2013

Analysis Ruth Segers

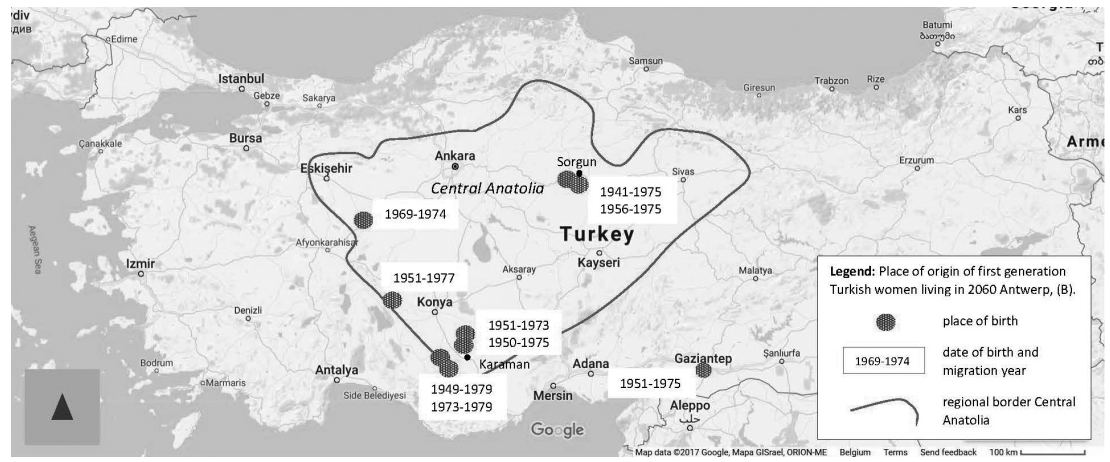

Illustration 2 Place of origin of first-generation Turkish women in 2060 Antwerp

Map Ruth Segers

In all cases, my first contact with the interviewees was on the doorstep of their home (mapped in Illustration 2), in an interbellum or after-war apartment, in a so-called worker's house. I greeted the tenant, offered to take off my shoes, or put them next to the other shoes at the door entrance. Then I was guided to the sitting room or kitchen where the interview took place. Dudu first introduced me and the research objectives, after which the participants agreed on having the interview recorded. Eight women asked to keep their names confidential. During the interview, I observed some guidelines for intercultural scientific interviewing (Bricki \& Green, 2007): sitting in a go degree angle with respect to the interviewee, not in an opposition; legs next to each other, not crossed; loosely making eye contact, never full eye contact. The two daughters did not veil while telling their 
stories, nor did Dudu, but the other women did. All but Dudu veil outside the home, yet, like all others, she considers herself a practising Muslim.

After the first interview, Dudu and I organised a feedback session to distinguish between her intentions to helping out the interviewees, my research agenda, and the stories I heard through her. Dudu had told me she wanted to be of assistance to me in order to improve, in her way and in some way through me, the lives of the involved interviewees. She had moved to the Antwerp suburbs and therefore did not fit the selected social location. We agreed on translating in a literal, transpersonal way during the interviews, e.g. 'I feel ...', not 'she says that she feels ....' However, this proved to be not manageable for Dudu. Therefore, in this paper, I hardly use personal quotes from interviewees.

Being a woman facilitated this study, not only by convincing women of doing an interview with a same sex person, as Dudu reported, but also by offering me a feeling of being on equal footing with interviewees. At the same time, the interviewees told me that being a single mom puts me in a vulnerable socio-economic position in their particular mind set.

\section{Sense of place: Turkish women's narrative}

There is one crucial decision that links the lives of six interviewed women: at the time they were teenage mums, their young husbands decided to take a chance and explore working abroad to provide for their families. They were attracted by the Belgian invitation to join workforces as 'guest workers'. Initially, it was a story of non-permanent economic migration; none of these men had the intention to stay abroad. Yet, as the period of work migration extended, this situation became unsustainable for the single adult households in Turkey. Two to eight years after the men's arrival in Belgium, the families sold their animals, food stock, and some belongings and vacated their houses. It was too hard for these women to stay in Turkey without partner.

The collected life stories evoke a recollection of past, previous, and ongoing sense of place experiences. The current experiences and feelings necessarily follow from what has been experienced before. Interestingly, the timing of changes to the different life phases or to changes in sentiments and attitudes regarding public place in this neighbourhood held by the interviewees run parallel with changes to the neighbourhood population 'layers' explained in the introduction. The first phase of experiencing place is situated in Turkey, and the second starts after the migration to Belgium, 
in the 1970s. In the narratives, a change of sentiments about the neighbourhood occurs in the 199os, and the divide is marked with the words: 'when the strangers came to the neighbourhood' (interview 8).

The narrative is summarised in the following three subsections, and followed by a map showing mentioned places in the neighbourhood.

\section{The women narrated to me about:}

1) growing up as a young woman in Turkey (1950-1970)

Summer months in Turkey were the hardest. From a very early age, the countrywomen were involved in doing chores around the home, making wicker mats, stitching, spinning wool, or attending the smallest. Outside chores were group activities including gardening, growing vegetables, attending the grape groves, or taking care of small cattle. It could be really warm outside. They wore small white head scarves and wide Turkish trousers with a longer blouse on top. The city woman recalls making grape molasses in courtyards and processing bulgur in the streets as a social activity. She effectively learned to read and write (so did the involved daughters, yet they mention sisters who did not). Reading or writing was not seen as something that would have contributed in helping out with the chores. So it definitely wasn't a priority for the countrywomen. After all, buying small stuff at the local market was based on an oral agreement. That was their responsibility after marriage. Doing the weekly shopping in the nearby town was a man's job.

The countrywomen told me that marriages or celebrations took place on a central open place, nearby the village. These were the occasions to meet boys. All women married when under 20. One (interviewee 2) was only twelve. The women explained to me their husbands decided to go to Belgium to earn money. The orphaned woman (interview 6) says she begged her husband to come along, she was fourteen when she had her first child and (social) life was hard in the country.

2) living in 2060 as guest workers' wives (1970-1990)

Going to the 'gavurlar' [unbelievers, a word with pejorative connotation] in Belgium for the first time was a huge adventure for all women. Although they were reassured to find that Belgians were people just like they were, everything else was 'new': the houses looked strange, so did the wallpaper, and even the market was different. They had never seen women in the streets without a scarf. European women seemed so 'naked'. Nevertheless they all started 
wearing European trousers with a long blouse on top and kept the typical white scarves.

Three women mention they were closer to their husbands in this period (the recently divorced city woman and the widow tell otherwise) and solidarity amongst women regarding child raising was bigger. The households visited further away Turkish families together and stayed overnight on a weekly basis. They would have long group talks. When the adult women heard new Turkish people would arrive, they all thoroughly enjoyed going to St-Jansplein for welcoming and helping the newcomers. Through the children they felt they were connected with Flemish neighbours (interviewees 1, 3, 4, 7, 8, and 9). They would find a package of nicely folded clothes at the door step or find the children get sweets of the neighbours and talk Dutch to them.

For the five illiterate women, experiences with places in Belgium always come with the undertone of being illiterate. One woman recounts about going to a place outside the neighbourhood with directions based on publicity boards. She fully lost her way: the posters on the publicity boards had been changed. Another woman used to bring her children to school, following one particular road stretch. She realised later there was a short cut, but she never dared to try. A third woman told me shopping to her means going to a place, taking prize labels, having them checked by her literate friend, and then go back to make a purchase. The orphaned woman tells me she deeply enjoyed a few secret walks to Stadspark, guided by two friends who could read. She regrets her friends have left the neighbourhood long time ago. Speaking Dutch is a problem too, she explains, as she is unable to share her feelings when in hospital. She understands what is being said, but cannot respond. Hence, taking her children to the doctor's used to be problematic too. She claims working outside the home would have helped to get connected, but, she says, I have children, I cook, and take care. Merely going outside does not help.

3) living in 2060 as Turkish migrant women (1990-2014)

During an extended period after their arrival all women fully focused on going back to Turkey. Every penny they earned was for investment in Turkey or for saving. They all shared with their families in Turkey too. This ended when their children got married. That is the time it deeply sunk in that they were going to stay in Belgium. Going back was no option anymore. They could never leave their children behind. 'Turkey has come here and the neighbourhood has become home.' (Turkish) people from the neighbourhood now mean more to them than their family in Turkey, even if they come from different regions (interviewees 1, 2, 3, 4, and 9). Still, they cannot miss going to Turkey. The orphaned woman dreams of returning permanently. Six of them have a house 


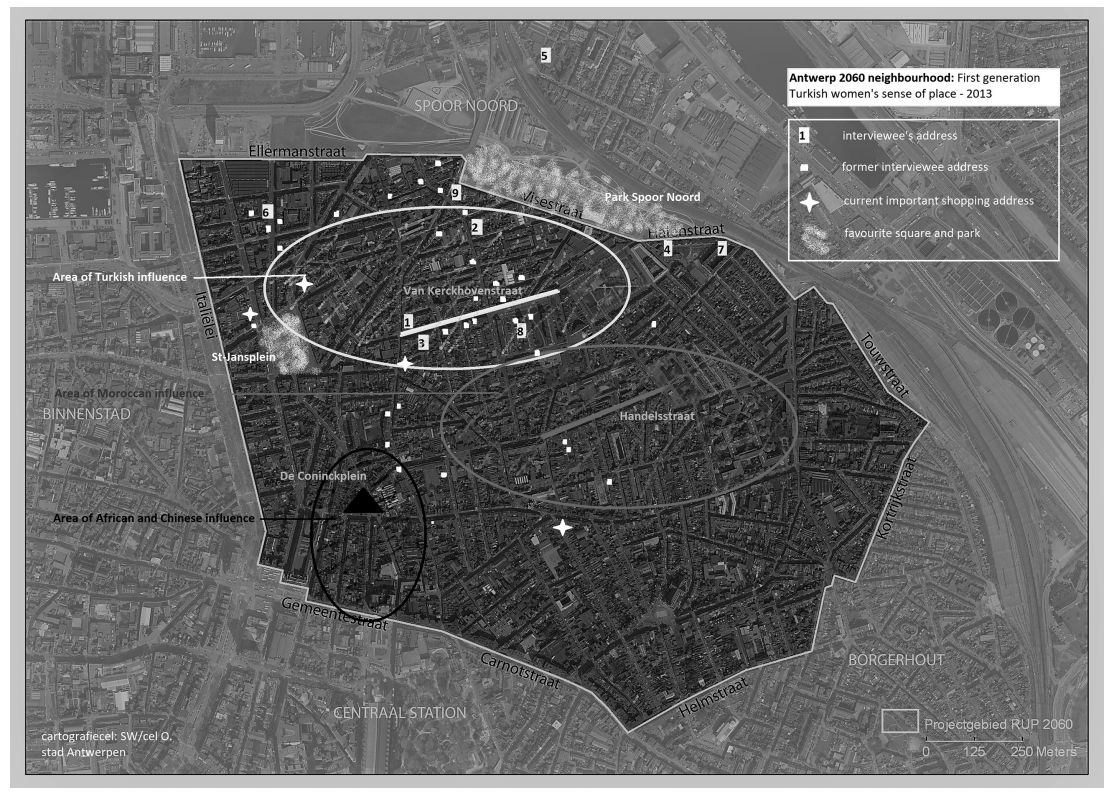

Illustration 3 Sense of place in the 2060 Antwerp neighbourhood for first generation Turkish women

Map Ruth Segers

there. The neighbourhood offers a social life and connection with their children; Turkey offers time to unwind with work to do in their garden. All have an insurance to be buried in Turkey.

All women and daughters mention feelings of particular unease when facing Turkish men in the streets. Especially when encountering men that are next of kin. Therefore, they avoid the Van Kerckhovenstraat [with many Turkish coffee bars, in the middle of the 'Turkish area' of the neighbourhood]. On sunny days, the stairs in front of the [St-Amandus] church are packed with Turkish men. That is why these women prefer to take the tram to pass that street. Four countrywomen and the divorced daughter claim they would rather go to Handelsstraat [ a major ethnic-Moroccan predominance - shopping street in the 'Moroccan area' of the neighbourhood] or the market [St-Jansplein]. All of them wear the headscarf when going outside. The women claim they have been better informed now (to not show their hair), it brings safety. The better off, married daughter maintains it is reclaimed piety that drives her.

Three countrywomen have had knee operations, the widow has had serious back operations. The latter says she used to be very thin when she was young... but that has changed. For these women, it is hard to walk more than 500 
metres. When they need to be somewhere, their children drive them. Still, they enjoy shortly going to the park (Park Spoor Noord) or going out. They assert there are not enough benches to sit on, nor are there enough trees to provide shadow. All of them claim the streets have changed since the 1970s. The initial Flemish inhabitants have left and now there are many people from Eastern Europe. Two countrywomen say they feel unease when encountering new Turkish people because they cannot distinguish Kurds from PKK members. It seems there is more poverty, dirt (needles), and noise on the streets now. They all avoid the De Coninckplein [with a concentration of African inhabitants] too. Now, five women connect with non-relatives at home, they have a weekly Koran group, where they discuss religion (and many other subjects).

Illustration 3 situates the narrative. It locates those places of which the sense of place is highlighted in the interviews: the Turkish and a Moroccan influenced area, the most important shopping locations, and the most favoured park and (market) square. From the locations of former and current interviewee addresses it is clear that, for the involved women, the "Turkish area' in particular and the neighbourhood at large is not a transition place (Saunders, 2011); it has become their home.

\section{Analysis of the narrative}

Three issues stick out when analysing the narrative. They all recur in social debates in relation to an 'integrating in society' narrative. The first issue is about language skills (a dimension of the category 'being in a precarious social-economic position'), the second issue is about gender tension, and the third is about the importance of belonging, a notion that strongly resonates with sense of place.

The first issue, not being able to converse in a prevalent language and not being able to read, are mutually reinforcing inabilities. These inabilities seriously impede social connection outside the household. It not only hampers their ability to ventilate emotions and needs to Dutch-talking people, it also makes navigating through public space quite demanding. This inability surfaced as a major problem from the moment the women entered the context of the Belgian society. However, while being in Turkey, being illiterate is not and has never been a pressing problem for them.

Over the three different periods, we see the emergence of adaptation of small spatial strategies (Yeoh \& Huang, 1998) in order to connect on an interpersonal level. Before migration, social contact is limited within the 
household with exceptional encounters in public place at the occasion of major transitional rites. In the period 1970-1990, the need for social connection is expressed in several instances and is met through sleepovers, meetings in the market square, neighbourhood shopping, and occasional trips to a further away park. It is the period with a relatively bigger influence of Flemish peers, whom they encounter in public spheres. In this period, the involved women started wearing 'European trousers' without overly paying attention to fully covering their hair. During the period 1990-2014, the nature of spatial strategies that offer a way out of isolation has altered. In this period, respondents rely more on interaction with Muslim peers. There are still parties for anniversaries and marriages, but not in the public sphere. Moreover, women explicitly withdraw from direct interaction in public spheres as can be seen in their wearing a veil and resigning to not being able to read or speak a foreign language. Physical limitations, the appearance of streets, the encounters on the streets, and non-accessibility of parks all play a role in this. In this period, the organisation of religiously inspired, weekly get-togethers amongst women in the private home take on an important position in their social life.

The second issue is about the tensions that are felt whenever Turkish men are encountered in the neighbourhood streets. The interviewed women all explicitly avoid the Van Kerckhovestraat, which is flocked with Turkish coffee houses. Taking a tram through it is an alternative option for many as it mitigates direct contact with the male gaze. At first sight, it looks like a gender issue, but when looking closer it becomes clear that location of origin plays a very important role. For it is Turkish men (that are next of kin or reside in the same neighbourhood) who are avoided, not Moroccan men, who are Muslim as well.

The intersection between the criteria being female, having been born in rural Turkey, and thus wearing a scarf is highlighted in the period 1990-2014. Amongst the involved women, a reference to instituted standards of Islamic orthodoxy prevails, yet references to parental and male kin authority are made as well. The body not only needs to be covered 'because of Allah's will', but also because of 'the father's will', 'your parents' will', or, in one occasion, out of piety. So, most women involved in this study cope with a fear of an authority figure by covering in places where social connection is possible, in the home as well as outside the home. I consider this fear of authority not as a specific cultural given. To me, this is information of a phenomenological nature: it can be observed in any group (Tuan, 1979). However, the way a solution is sought for handling this fear is culturally informed. Wearing a scarf is historically and culturally rooted in the upbringing of the involved women. Taking off the veil would not only imply taking on another relationship with 
their own body, it would also imply a re-negotiating of their relationship with others, women and men (Fadil, 2011). In other words, it would challenge the involved women's way of handling intrapersonal and, as a consequence, interpersonal interaction in and outside the home.

Relationships to places, seen as a life-long process, are the third issue. The statement 'Turkey has come here' is meaningful to me. It says 'the place I belong to has come to this neighbourhood'. This does not mean Turkey has disappeared as a meaningful place; Turkey remains 'the place I belong to'. Although eight out of ten interviewees do not own a house in Belgium, all but one have a modest or nice property in Turkey. House ownership in Turkey grants these women the ability to reside in Turkey for prolonged vacation periods. Gardening is a very important activity in Turkey, which actively and passively nourishes this feeling of belonging (Tuan, 1975) in them through its connection with the soil and fruits of their origin. What is more, Turkey is unanimously chosen as their 'ultimate' place of destination.

The expression 'the neighbourhood has become home' can be understood as: 'The neighbourhood is the space that connects me with my children'. For it is this bond with their children that colours the neighbourhood as 'a symbolic space of familiarity, comfort, security, and emotional attachment' (Tuan, 1975). This bond is a stronger basis of belonging to a place or feeling 'at home' than the relationship with a 'domestic(ated) material space'. A domestic space in the neighbourhood was available for them in a period of over 15 years. Yet only in the 199os, coinciding with the first marriages of their children, came the realisation that the neighbourhood in fact is a 'home' for them.

Hence, from this moment onwards, I see a deduplication of 'feeling at home' in the interviewed women: they feel truly at home in two places; neither place affords the full sentiment of 'being at home'. It is only by exploring and acknowledging the ways in which the involved women re-enact in a self-owned way what links them to their roots that we can understand the significance of this process. Their desires affect and will have been shaped by non-liberal traditions, as we see in their leaning upon wearing a veil and taking the illiteracy aspect as a given issue. The western world perceives this behaviour as subordination to men. As such, the proscription from public place and the means to control their social interactions in the public sphere draw upon structures of inequity located in the home and elsewhere (Yeoh \& Huang, 1998). Alternatively, and simultaneously, this behaviour can also be considered as a desire to express 'belonging, a desire to belong to certain intersectional locations - locations that are manufactured by hegemonic discourses of culture, but also by articulatory 
practices around family, gender, age, religion, sexuality, or socio-economic class (Prins, 2006). The 'environmental past' of these women is ingrained in their memories and reproduced in adjusted ways in their everyday life (Manzo, 2005). Through their attachment to two different geographically locatable places, the involved women acquire a sense of belonging and purpose that gives meaning to their lives and informs their actions in dealing with interconnectedness in public spheres.

As Relph (1976, p. 20) points out, 'without exception, the home is considered to be the "place" of greatest personal significance in one's life, in fact "the central reference point of human existence". In this instance, we see an effective yearly travelling from home to home. The relationship between both places of home can be seen as a reflection of a 'journey' (Manzo, 2005) from the interviewed women, which not only reflects their dealing with physical boundaries, but also shows us how their feelings of comfort, belonging, and self-affirmation can transcend physical boundaries. This belonging in two places goes hand in hand with a sacrifice of social connectedness: in present time, social connection is more important in the neighbourhood, yet this connection is severed yearly for a trip of several months to Turkey. Despite the fixity of their identities as 'women migrants' who, according to dominant discourse, hardly have a place in public space, these women do not necessarily accept these representations as immanent. Instead, like other subordinate groups, they are able of working with what Foucault (1982) calls 'little tactics of the habitat'. These women find greater degrees of freedom, in expressing their selves in a way they feel is congruent with whom they feel they are, in impressing their own cultural 'style' on the public landscape - through dressing, speech, behaviour, and an inversion of public norms - than in active, deliberate strategies of resistance (Yeoh \& Huang, 1998; Mahmood, 2001).

\section{Where do we go from here?}

This case study informs us about first-generation Turkish women's sense of place of the 206o neighbourhood in Antwerp. What they have come to see as appropriate behaviour in public spheres can only partly be seen as influenced by social interaction with peers or figures of authority. The other part is influenced by a 'duplicated feeling of being at home'. Through their bond with their children, they have come to feel inevitably attracted to the neighbourhood, but the attachment to their country of origin is still very strong. This dual attachment perspective is important for the conception of public 
space because these women as social actors/agents construct and reconstruct places starting from their own realities, meanings, and experiences. What stands out is the very limited claim on traditional public places in the neighbourhood. It is compelling to find that women, in finding individual solutions to collective problems, create situations where they assist in making the causes of a problem invisible and therefore unresolved (Horelli \& Vespä, 1994). Traditional public place still is a masculine realm. And, to make it more of a space where women are at ease, it might need some more social AND spatial adjustments, because spatial patterns do influence our sense of gender (Heynen, 2005) and sense of culture and vice versa.

\section{Word of thanks}

In warm appreciation of the hospitality of the translator and interviewees and their gratitude for being able to tell their stories. Some of which had never been vented before.

Bir fincan kahve olsan 40 yil kateri olur. Loosely translated: 'If you drink a cup of coffee together, friendship is tenable for 40 years....

\section{Bibliography}

Baumeister, R.F., \& Leary, M.R. (1995). The need to belong: Desire for interpersonal attachments as a fundamental human motivation. Psychological Bulletin, 117 (3), 497-529.

Blommaert, J. (2014). Infrastructures of superdiversity: Conviviality and language in an Antwerp neighbourhood. European Journal of Cultural Studies, 17(4), 431-451.

Bricki, N., \& Green, J. (2007). A guide to using qualitative research methodology [brochure]. London: Health Services Research Unit, London School of Hygiene and Tropical Medicine.

Crenshaw, K.W. (1991). Mapping the margins: Intersectionality, identity politics, and violence against women of colour. Stanford Law Review, 43(6), 1241-1299.

Decommere, A. (2014). Alaturka - Belgian documentary on Turkish integration. Retrieved on May, 20, 2018. https://www.youtube.com/watch?v=k5HYO7QAeds.

Divercities (2013). Antwerp. Retrieved May 20, 2018 via: https://www.urbandivercities.eu/antwerp/.

Erfgoedcel mijn Erfgoed (2014). 5o jaar Turkse migratie, Houthalen. Retrieved on May 20, 2018. https://www.youtube.com/watch?v=Kdu 50 OPk6cNg.

Fadil, N. (2011). Not-/unveiling as an ethical practice. Feminist Review, 98(1), 83-109.

Foucault, M. (1982). The subject and power. Critical Inquiry, 8(4), 777-795.

Harrison, S., \& Dourish, P. (1996). Re-place-ing space: The roles of place and space in collaborative systems. Proceedings of the 1996 ACM conference on computer supported work.

Heynen, H. (2005). Modernity and domesticity. Tensions and contradictions. In H. Heynen \& G. Baydar (Eds.), Negotiating domesticity; Spatial productions of gender in modern architecture (pp. 1-29). London: Routledge. 
Horelli, L., \& Vespä, K. (1994). In search of supportive structures for everyday life. In I. Altman \& A. Churchman (Eds.), Women and the environment: Human behaviour and environment (pp. 201-226). New York: Plenum.

Lutz, H. (2002). Intersectionality's (brilliant) career - How to understand the attraction of the concept? (Working paper No. 1). Retrieved from Gender, Diversity and Migration, Goethe University Frankfurt: http://www.goethe-university-frankfurt.de/6oo27661/ Gender_-Diversity_-and-Migration.

MacCall, L. (2005). The complexity of intersectionality. Journal of Women in Culture and Society, $30(3), 1771-1800$.

Mahmood, S. (2001). Feminist theory, embodiment, and the docile agent: Some reflections on the Egyptian Islamic Revival. Cultural Anthropology, 16(2), 202-236.

Massey, D. (1994). Space, place and gender. Minneapolis: University of Minnesota Press.

Manzo, L. (2005). For better or worse: Exploring multiple dimensions of place meaning. Journal of the American Planning Association, 25, 67-86.

Moulaert, F. (2000). Globalization and integrated area development in European cities. Oxford: Oxford University Press.

Moulaert, F., \& Christiaens, E. (2010). The end of social innovation in urban development strategies? The case of BOM in Antwerp. In F. Moulaert, F. Martinelli, E. Swyngedouw, \& S. Gonzalez (Eds.), Can Neigbourhoods Save the City? Community Development and Social Innovation (pp. 238-251). London: Routledge.

Panorama Jambers (1988). De Seefhoek. Retrieved on May 20, 2018. https://www.youtube.com/ watch?v=ukMHZE_97HE.

Prins, B. (2006). Narrative accounts of origins: a blind spot in the intersectional approach? European Journal of Women's Studies. 13(3), 277-29o.

Relph, E. (1976). Place and placelessness. London: Pion.

Rose, G. (1995). Place and identity: A sense of place. In D. Massey \& P. Jess (Eds.), A place in the world? Places, cultures and globalisation (pp. 87-132). Oxford: Open University Press.

Saunders, D. (2011, December 17). Why did Antwerp's immigrant ghetto get so bad? The Globe and Mail. Retrieved from https://www.theglobeandmail.com/news/world/ why-did-antwerps-immigrant-ghetto-get-so-bad/article4181383/.

Stad Antwerpen (2018). Demografie (Rapport demografie, postzone Antwerpen Noord (206o)). Retrieved from Stad Antwerpen Stad in cijfers databank: https://stadincijfers.antwerpen.be/ databank/Report?id=demografie\&input_geo=postzone_206o.

Tuan, Y.-F. (1975). Place: An experiential perspective. Geographical Review, 65(2), 151-165.

Tuan, Y.-F. (1979). Landscapes of fear. New York: Patheon Books.

Yeoh, B. \& Huang, S. (1998). Negotiating public space: Strategies and styles of migrant female domestic workers in Singapore. Urban Studies, 35(3), 583-6o2.

\section{About the author}

Ruth Segers (Belgian, 1969) is a member of the Planning and Development research group of the Department Architecture, KULEUVEN, Belgium. In her doctoral research, 'The interacting subject in urban public space, in need of places for interpersonal cooperation', she studied the relationships between public space and interpersonal interaction. 